\title{
Time on Task: Perceived and measured time in online courses for students and faculty
}

\author{
Cheryl Delgado *, Linda Wolf \\ School of Nursing, Cleveland State University, United States
}

Received: July 23, 2016

Accepted: November 24, 2016 Online Published: December 19, 2016

DOI: $10.5430 /$ jnep.v7n5p27

URL: http://dx.doi.org/10.5430/jnep.v7n5p27

\begin{abstract}
Objective: A cross sectional, online survey study examined active course time and activity for students and faculty in online courses compared to their perceptions of time.

Methods: Student self-reports of their estimated course time and percentage of time on individual tasks, and faculty estimates of student time as well as their own course activity time were obtained. This was compared to actual individual and course summary activity data as recorded by the learning platform (Blackboard). Descriptive and $t$ tests were analyzed using IBM SPSS Statistics 22.

Results: Students and faculty generally agreed on the amount of time spent on task in all areas examined (discussion, assignments, tests and quizzes, messaging and communication, information searches, checking instructions and rubrics), but were significantly different for time spent off-line preparing Discussions and Assignments. Discussions, content materials, messaging and grade records were the most active areas. Students believed that the work in the online courses was more appropriate than did their instructors. There was no correlation between active course time and course grades.

Conclusions: Students and faculty generally agreed in the amount of time spent actively in an online class, but grossly overestimated their time online. On line time did not correlate to course grade. The study adds to better understanding of the time sent in online courses.
\end{abstract}

Key Words: Online courses, Research, Online course work time

\section{INTRODUCTION}

Entire programs in many schools of nursing, public, private and for for-profit, are now online. These programs are popular and even perhaps a preferred, model for post licensure professional education in nursing. The advantages of online courses are well documented. ${ }^{[1,2]}$ Online courses have been found to be as effective as traditional courses ${ }^{[3,4]}$ and have spread rapidly world-wide. ${ }^{[5]}$

Reports exist in the literature on the organization of online courses $^{[6]}$ as well as the quality of online instruction. ${ }^{[7,8]}$
More recent research has focused on the development of interpersonal online connectivity and community. ${ }^{[9,10]}$ At the start of the twenty-first century some education researchers looked at the impact of online teaching on faculty workload. ${ }^{[1-13]}$ Generally earlier research supported findings of increased workload for faculty, longer preparation times and complex course structures. Despite this, only two articles were found in CINAHL within the past seven years on the time spent in online coursework and neither of these were research reports. The literature primarily discusses students' need for time management and self-discipline for completStates.

*Correspondence: Cheryl Delgado; Email: c.delgado@csuohio.edu; Address: School of Nursing, Cleveland State University, Cleveland, United 
ing assignments and coursework when enrolled in online courses ${ }^{[14]}$ Information on desired learning styles is obtainable and indicates stable preferences for online courses for post licensure students. Students enrolling in online courses were motivated by time and technology factors, such as flexible class participation schedules and comfort with computers. ${ }^{[15,16]}$ There is a dearth of recently published information on teaching time requirements and perceptions of student time on task in online nursing courses.

At our institution, a large Midwestern university, we have two completely online nursing programs (RN-BSN and graduate Master's) in addition to traditional face to face programs. Some faculty teach in both formats and universally believed that the time commitment for online classes does not translate into fewer hours, only more flexible hours. We were interested in discovering if our perception regarding the amount of time students were working in the online courses was accurate and if the perception that student work was equivalent to face to face classes was correct. We were also interested in faculty time in on line courses as a workload issue.

\section{MethodS}

\subsection{Design}

Our study was designed as a cross-sectional, online survey of students and faculty in completely online courses in both undergraduate and graduate programs. A plan was developed to collect data from three sources: subjective survey data of perceptions of activity from faculty and students and objective numeric data recorded in the online Learning Management System (LMS). Students were asked at the end of each semester during the study about their level of experience with online courses, and for currently enrolled classes, to estimated hours spent on line for estimated percentages of time spent on line in selected course areas such as preparing discussion and assignments, searching or navigating the course, checking assignments and grading rubrics, posting discussions and assignments, reading or viewing content, and communicating with faculty or others in class. Faculty were asked at the same time for their perceptions of student activity in the same categories, for estimates of their time in similar activity categories and about their experience in online teaching. Actual course activity data was also retrieved from our learning management system which has the capacity to track data regarding 'hits' or the number of times a course enrollee accesses a particular course area and in some situations records the actual amount of time logged into particular course areas.

Because all our online courses share a standardized content organization, we felt that individual course differences in terms of ease of course navigation and level of information availability would impact minimally. Courses selected for the study were non-clinical, asynchronous pure online classes.

This existing data was downloaded by each course instructor at the end of the semester and was a mix of aggregate and individual data. Data on individual student activity was limited to access of the number of student visits to specific activity areas with in the course and measured total time in the course for the semester. Aggregate data were averages of all student time in any single course and in course areas that were tracked. The tracked areas within courses were set by the university contract with the LMS.

After IRB approval we collected information at the close of four consecutive semesters starting in January 2015 through May 2016. Students and faculty signed informed consents prior to participation. In their consent, students also agreed that course grades could be accessed and used when deidentified and assigned study codes for data analysis. All statistical calculations were done using IBM SPSS Statistics 22.

\subsection{Sample and data collection}

No demographic data was collected from student participants to preserve confidentiality, but a descriptive profile of students enrolled in the school of nursing is known from annual enrollment analyses done by the university's department of Institutional Research. Students are predominantly Caucasian (73\%), African-American (13\%) and female (86\%). In the undergraduate programs they are enrolled as full time students unless completing degree requirements at the end of their enrollment, but at graduate level most are part time students (76\%) and nearly 100\% are employed full time.

Student participant privacy was not guaranteed as grade data and course data retrieval required the cooperation of faculty, but information on grades was collected only for those students who agreed to participate and was de-identified and relabeled with a study code by the researchers. In other areas such as access frequencies and time in the course, aggregate data was obtainable and preferentially used. As a result, an inconsistent $\mathrm{N}$ may be noted in several statistics. Ten totally online courses taught by four different faculty in both undergraduate (RN-BSN post licensure) and graduate level (MSN) programs were examined. Seven were graduate level; three were undergraduate level. Eight of the courses surveyed are Quality Matters certified and faculty are required to complete an in house certification for on line teaching. The total enrollment in all courses used in the study was 239. Class enrollments ranged from 5 to 28 with a mean of 23.9. Fortyfour individual students participated. Many students participated as enrollees in more than one course as they progressed 
in the curriculum. Students in both the undergraduate and graduate programs surveyed progress in cohorts.

\section{RESUlts}

There were differences in the experience of both faculty and students in online courses. Some students had never taken an online course previously, but a few reported as many as 20 . The mean number of previous online courses for students was five. Faculty online teaching experience ranged from three to 55 previous courses with a mean of 39.

There was more consistency than disagreement between faculty and students in their estimates of student time on tasks in courses. Students estimated more time in non-learning activities such as searching for information and communication than faculty estimates of student time in those areas. Low faculty estimates for these student activities may indicate a need to revisit course organization and labeling of content. A summary of these estimates is presented in Table 1 .

Table 1. Comparison of student/faculty estimates of student time on task in course

\begin{tabular}{lll}
\hline Variable & Mean weekly \% estimate from Student & Mean weekly \% estimate from Faculty \\
\hline Weekly hours working in course & $6.72 \%$ (range 2-30 hours week) & \\
Weekly hours working off-line & $11.05 \%$ (range 2-48 hours week) & \\
\% of time reading course material & $19.6 \%$ & $23.45 \%$ \\
\% of time downloading material & $5.11 \%$ & $8.82 \%$ \\
\% of time drafting discussions & $18.02 \%$ & $18.55 \%$ \\
\% of time drafting assignments & $19.02 \%$ & $22.73 \%$ \\
Searching in course & $11.09 \%$ & $3.27 \%$ \\
Checking Messages & $5.08 \%$ & $1.01 \%$ \\
Quizzes and tests & $2.44 \%$ & Inconsistent \\
Checking assignment instructions & $4.93 \%$ & $1.73 \%$ \\
Checking grading rubrics & $3.43 \%$ & $1.09 \%$ \\
\hline
\end{tabular}

Student responses to questions on the number of credit hours assigned as appropriate based on the amount of work, and the comparison to face to face course time indicated that students generally felt the amount of work was not unexpected and not perceived to be excessive. Faculty tended to disagree, sharing their perception that student and faculty work was more than expected for the assigned credit hours and more than what was experienced in face to face classes. This is summarized in Table 2.

Table 2. Online vs. face to face classes: student and faculty perceptions

\begin{tabular}{|c|c|c|c|}
\hline \multirow{2}{*}{ Responses of } & \multicolumn{3}{|c|}{ Estimate of time devoted to online class } \\
\hline & Less than expected & About expected & More than expected \\
\hline Students & $2.2 \%$ & $57.8 \%$ & $40 \%$ \\
\hline \multirow[t]{3}{*}{ Faculty } & $0 \%$ & $45.5 \%$ & $54.5 \%$ \\
\hline & \multicolumn{3}{|c|}{ Assigned Credit Hours appropriate for class work } \\
\hline & Less than appropriate & About right & More than appropriate \\
\hline Students & $2.2 \%$ & $77.8 \%$ & $20 \%$ \\
\hline \multirow[t]{3}{*}{ Faculty } & $0 \%$ & $27.3 \%$ & $72.7 \%$ \\
\hline & \multicolumn{3}{|c|}{ Hours of work compared to face to face class } \\
\hline & Less than face to face & No difference & More than face to face \\
\hline Students & $2.3 \%$ & $34.1 \%$ & $63.6 \%$ \\
\hline Faculty & $0 \%$ & $0 \%$ & $100 \%$ \\
\hline
\end{tabular}

Course log-ins were spread throughout the week fairly evenly with a small spikes on Thursday and Sunday, corresponding with a commonly used due dates for discussions and other written assignments. The next most popular day for student log-ins was Thursday which was close to the second most common work due date on Friday midnight. Course 
log-ins by day are presented in Figure 1. Course calendars are included in all courses and assignments and due dates are posted at the start of each course in the syllabus and course introductions. Assignments are not changed during the courses, but an instructor may allow for late submissions based on individual need. Students are aware at the start of each course what work is to be done and when it is due.

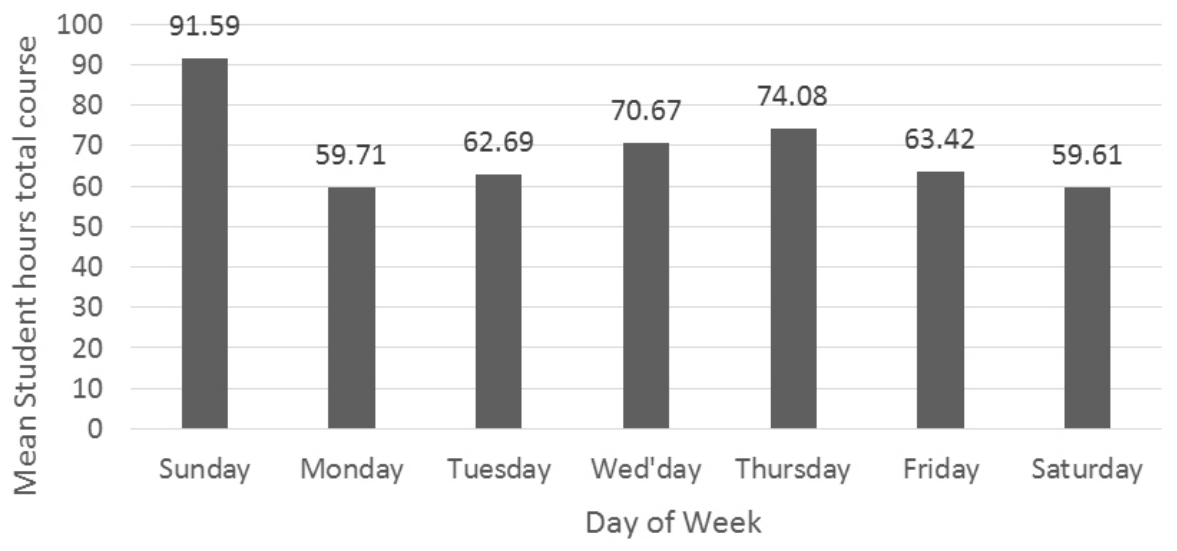

Figure 1. Mean student activity by day for all courses

The mean total time students were logged into courses was 481.78 hours (range 175.37-981.23). Student responses to questions about the percentage of weekly time devoted to on line course work varied wildly and some student estimates were markedly excessive, claiming more than 300 percent total time. In these cases, if evidence pointed to students confusing the request for percentage of time estimates with hour estimates of time and the weekly estimates as hours, were possible to achieve, a decision was made to use the data by calculate percentages from information provided. One obvious outlier was dropped from the database calculations as it claimed more hours than all weekdays combined. The mean length of time for all students to be logged into a course was 26.68 hours (range 1.24-205.95). There was no significant difference between the undergraduate and graduate level students in total or mean course times.
Not all faculty tracked student hours logged into specific course areas, but the number of times an area was accessed or 'hit' was consistently documented. The areas that were not consistently monitored were those that had to do with the way each student set up their course appearance and "to do task lists". Students were most active in discussion areas (mean 531.08), content (mean 295.55) and messages or emails (mean 89.95) in that order. A comparison of the most active course areas is presented in Figure 2. Grades were checked more often than grading rubrics. There were no significant correlations between student time in a course and course grades. Students with low course times were consistently students identified by faculty as 'at risk', but high performing students also logged high total course times. One explanation for this is that students in academic distress and those who were at the top of the class may have cancelled each other out statistically.

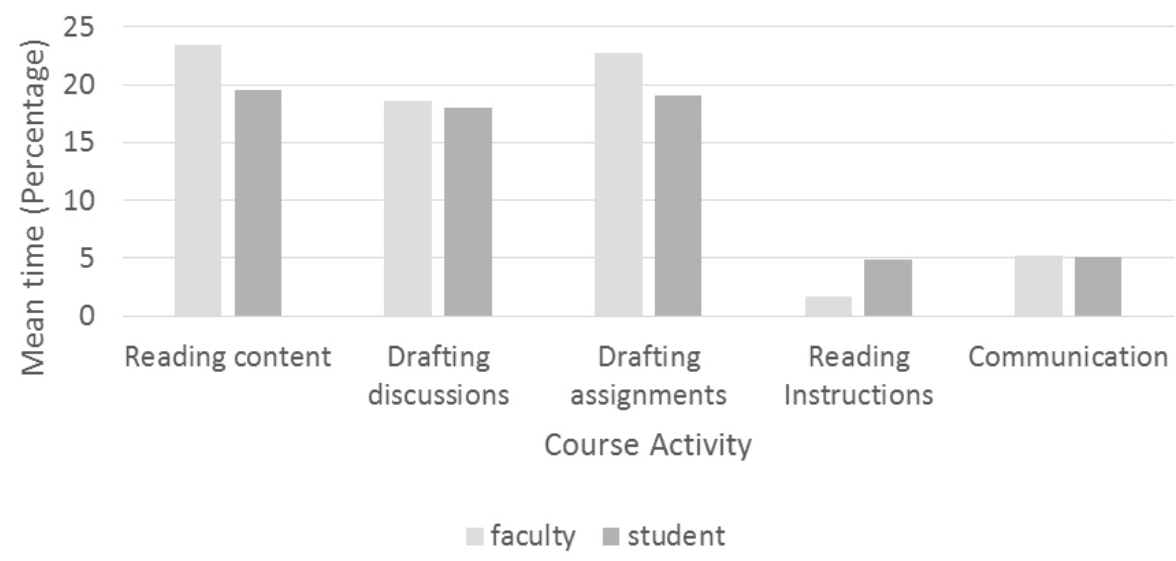

Figure 2. Comparison of faculty/student time estimates of selected course activities 
Faculty self-reported their most active course areas as responding to discussions (mean weekly time $37.27 \%$ ), reading and grading assignments (mean weekly time $30.77 \%$ ), responding to communications from students (weekly mean time $7.18 \%$ ), upgrading and changing course materials (mean weekly time $4.27 \%$ ) and troubleshooting the LMS (mean weekly time $1 \%$ ), in that order. There were wide variations in the amount of time devoted to particular tasks by different faculty. Discussion times were highly variable ranging from $25 \%$ to $60 \%$ of weekly total time, depending on course content. Course material revisions and upgrades also differed as some preferred to complete this work before the course opened, but all agreed that this was a necessary and time consuming task. This is consistent with the findings of Anderson and Avery ${ }^{[11]}$ who noted that most preparation for web courses is done in advance. Troubleshooting problems with the LMS was rare, but stressful as could affect the student's ability to complete work in a timely manner and so received high priority.

\section{Discussion}

\subsection{Contributions to the profession}

The information obtained in this survey adds to the research available for online education quality, outcomes and design. Knowledge about the amount of time students and faculty spend in course activities as compared to their perceptions of the same can be examined to evaluate course credit hour assignments, faculty and student workloads and the organization and structure of online courses. In our online programs, the amount of time faculty spend active in their courses is greater than the time spent by students. Faculty are expected to respond to student queries and posts within 24-48 hours and most $\log$ in daily and more than half of the faculty surveyed extend this level of engagement through weekends.

Because students and faculty in online courses frequently communicated more regularly through messaging and discussions than in face to face classes, this engagement with the student can be a positive factor for reducing attrition. It is not as easy for a student to 'sit back' in a class when regular posts in discussions is a requirement. More consistent tracking of time in course areas could be designed into future research and different or expanded tracking in specific course areas is theoretically feasible. Faculty should be familiar with the potential value of course activity tracking in identifying and monitoring students at risk. Repeated access to particular areas may raise red flags for faculty to query students on the reason for the repeated visits. Students not logging into a course regularly can also be identified and contacted for follow up before they find themselves irretrievably behind in the course work.

Published by Sciedu Press

\subsection{Study limitations}

There are limitations in the study that must be considered. This was a small sample of students and faculty. Missing data from incomplete or unusable responses to some survey questions could have affected the results. The limitations inherent in the use of existing data posed a significant problem as the data collected by the LMS was not all that we would have liked to have collected. We would have liked more detailed information on measured individual student times. Off line work could not be measured and estimates did not appear consistently accurate. This limitation may have considerably skewed assumptions regarding the total amount of time students spent engaged in course work. Some students may have downloaded material for reading off line and others may have read screens while logged in. In some courses quizzes are a graded activity and in others short tests or quizzes are not graded but serve as a learning checkpoint for students. The measured data from that activity area may be misleading.

Despite these concerns, our results did not conflict with those from previous studies, and may support the findings of Anderson and Avery ${ }^{[11]}$ regarding faculty workload and course preparation time. This study also supports previous speculation on increased student-faculty engagement in an online environment. ${ }^{[17]}$ Participating faculty agreed that they were able to develop relationships with students and may have learned to know them better than in a larger face to face class.

\section{Conclusion}

The online format for delivering educational programs continues to proliferate as a preferred method of course delivery. Overall, faculty and students were fairly consistent with the amount of time spent in differing areas of the courses. This study revealed that at risk students had fewer sign on times in class. This could be used by faculty as a means to not only to track at risk students, but to develop learning contracts with at risk students to promote student success.

The popularity of online courses, especially with millennial students, ${ }^{[18]}$ ensures its place in the curriculum as a presentation strategy. Because we cannot assume that the amount of time and teaching strategies traditionally used in face to face classes are transferable to the online milieu, faculty need to continue exploration of modern student engagement. Further investigation of time on task will assist in identifying accurate credit hours for online courses, as well as providing additional information on faculty workload for revision, design and development of online courses. Equally as important is for faculty to investigate the highest areas of "hits" as this may indicate needed areas of change or modifications in 
the course set-up.

\section{ACKNOWLEDGements}

The authors acknowledge the contributions of the faculty who assisted in the data collection and participated in the survey, the support of the eLearning department at Cleveland State University.

\section{CONFLICTS OF INTEREST DiSClOSURE}

The authors declare that there is no conflict of interest.

\section{REFERENCES}

[1] Baldwin KM, Walker C, Evans E. Educational Innovations: increasing nursing faculty in rural Texas through online education. Journal of Nurs Ed. 2004; 43: 555-557.

[2] McAlpine H, Lockerbie L, Ramsay D, et al. Evaluation a web-based graduate level nursing ethics course: Thumbs up or thumbs down? Journal of Cont Ed in Nursing. 2002; 33: 12-18. PMid:15887355

[3] McCutcheon K, Lohan M, Traynor M, et al. A systematic review evaluating the impact of blended learning vs. face to face learning of clinical skills in undergraduate nurse education. Journal of Advanced Nursing. 2005; 71(2): 255-270. PMid:25134985 https://doi.org/10.1111/jan.12509

[4] Avery MD, Cohen BA, Walker JD. Evaluation of an online graduate nursing curriculum: examining standards of quality. Journal of Nurs Ed. 2008; 5(1): 1-17. https://doi.org/10.2202/1548-923x. 1538

[5] Zhao Y, Lei B, Yan B, et al. What makes the difference? A practical analysis of research on the effectiveness of distance education. Educational Technology and Society. 2006; 14: 224-235.

[6] Moore P, Hart L. Strategies for teaching. Nursing Research Online. 2004; 51(2): 123-128.

[7] VandenVusse L, Hanson L. Evaluation of online course discussion: computers in faculty facilitation of active student learning. Computers in Nursing. 2000; 18(4): 181-188.

[8] Blood-Siegfried JE, Short NM, Rapp CG, et al. A rubric for improving the quality of online courses. Nursing Education Scholarship. 2008; 5(1): 13. https://doi .org/10.2202/1548-923x. 1648

[9] Mastel-Smith B, Post J, Lake P. Online teaching "Are you there, do you care? Journal of Nurs Ed. 2015; 54(3): 145-151. PMid:25692748 https://doi.org/10.3928/01484834-20150218-18
[10] Cox-Davenport RA. A grounded theory of faculty's use of humanization to create online course climate. Journal of Holistic Nursing. 2014; 32(1): 16-24. PMid:23926215 https://doi.org/10.117 7/0898010113499201

[11] Anderson KM, Avery MD. Faculty teaching time: a comparison of web based and face to face graduate nursing courses. Int Journal of Nursing Ed Schol. 2008; 5(1): 1-12. PMid:18241197 https://doi.org/10.2202/1548-923X.1539

[12] Sellani RJ, Harrington W. Addressing administrator/faculty conflict in an academic online environment. Internet and Higher Education. 2002; 5(2): 131-145.

[13] Smith G, Ferguson D, Caris M. Teaching on-line vs face to face. Journal of Technology Systems. 2001-2; 30: 337-364.

[14] Alexander S, Hoy H. Supporting learner success. In: K Frith, D Clark, ed. Distance education in nursing. 3rd ed. New York, NY: Springer; 2013. 65-80.

[15] Doyle NW, Jacobs N. Accommodating student learning styles and performances in an online occupational therapy course. Work. 2013; 44(3): 247-253. PMid:23324674

[16] Wills CE, Stommel M. Graduate nursing students precourse and postcourse perceptions and preferences concerning completely web based courses. Journal of Nurs Educ. 2002; 41(5): 193-201. PMid: 12025862

[17] Young JR. The 24 hour professor. Chronicle of Higher Education. 2002; 48(38): A31-33.

[18] Montenerey SM, Walker M, Sorenson E, et al. Millennial generation student nurses' perceptions of the impact of multiple technologies on learning. Nurse Education Perspectives. 2013; 34(6): 405-409. https://doi.org/10.5480/10-451 